\title{
Rare Case of Lipoma Necrosis Mimicking Liposarcoma: Case Report
}

\author{
M. Ouali Idrissi, R. Zerhoudi, F Abakka*, B. Boutakioute, N. Cherif Idrissi Guenouni
}

Department of Radiology AR-RAZI Hospital, UHC Mohamed VI Marrakech

DOI: $10.36347 /$ sjmcr.2021.v09i01.018

| Received: 15.12.2020 | Accepted: 26.12.2020 | Published: 26.01.2021

*Corresponding author: Abakka Fatima Zahra

Abstract

Case Report

A lipoma is one of the most common benign tumours and can develop at any location in the body. However, cases of necrotic lipoma are rarely described and imaging findings of necrotic lipomas is scarce. In the present case, we describe the case of a 59-year-old woman with necrotic lipoma in the right side of her neck, which mimic liposarcoma on imaging.

Keywords: lipoma, tumours, imaging, neck.

Copyright $\odot 2021$ The Author(s): This is an open-access article distributed under the terms of the Creative Commons Attribution 4.0 International License (CC BY-NC 4.0) which permits unrestricted use, distribution, and reproduction in any medium for non-commercial use provided the original author and source are credited.

\section{INTRODUCTION}

Fat necrosis within large lipomas is described in literature, but remains rare [1]. Clinically the patient may be asymptomatic or may present such symptoms as pain, skin induration, ecchymosis, skin retraction, or skin thickening. A variety of causes of fat necrosis have been reported, including trauma, collagen vascular disease, myeloproliferative disorders, and complications of pancreatic disorders such as in disseminated fat necrosis [2].

Lesions may have a variable appearance on imaging, ranging from small, spiculated, non encapsulated lesions to large, encapsulated mass-like lesions, necessitating differentiation from malignant soft tissue tumors.

We present a case of lipoma necrosis of the neck initially felt to be suspicious for a liposarcoma.

A lipoma is one of the most common benign tumours and can develop at any location in the body. However, cases of necrotic lipoma are rarely described and imaging findings of necrotic lipomas is scarce. In the present case, we describe the case of a 59-year-old woman with necrotic lipoma in the right side of her neck, which mimic liposarcoma on imaging.

\section{Case Report}

A 59-year-old woman presented with a 1-year history of a subcutaneous nodule in her neck. It had rapidly enlarged within the last three months, and become painful. Her past and family histories were unremarkable. A physical examination revealed a wellmobile, large, soft subcutaneous mass in the right side of her neck.

Magnetic resonance imaging (MRI) showed that a $20 \times 30 \mathrm{~cm}$ well-circumscribed tumor was located beneath the facia of SCM muscle with high signal intensities on both T1- and T2- weighted images and signal attenuation on fat suppression sequences, which indicated a lipomatous tumor.

Inside the tumor, there were multiple thickened septa with gadolinium enhancement, which was consistent with atypical lipomatous tumor (Figures $1 \& 2)$.

Surgical excision has been recommended, and the results accords with the diagnosis of lipoma with fat necrosis foci, proven histologically. 


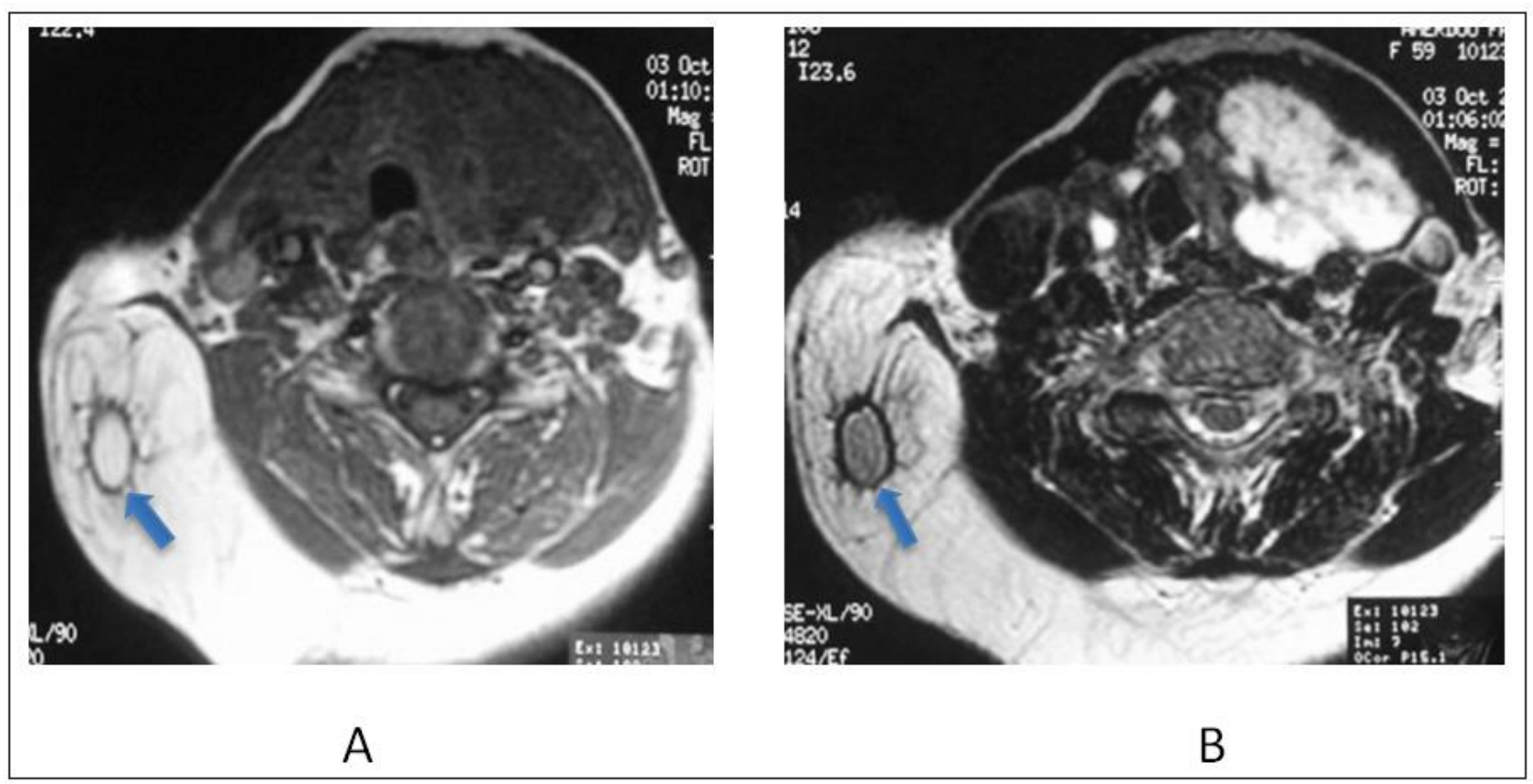

Fig-1: Axial T1-weighted (A), Axial 2-weighted (B) images showed well circumscribed tumor located beneath the right SCM muscle with high signal intensities (arrow). Inside the tumor, there were multiple thickened septa

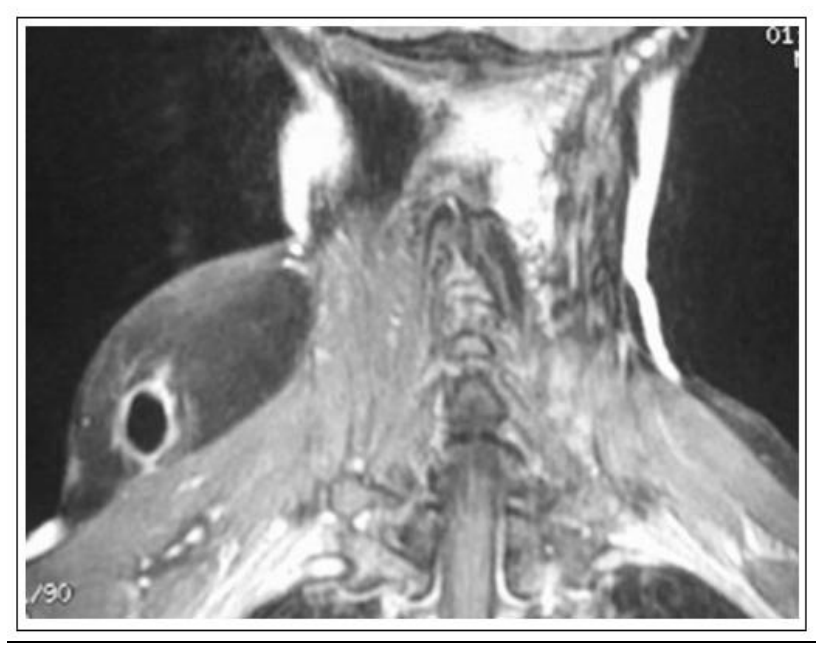

Fig-2: Coronal Fat-saturated T1-weighted image showed multiple prominent thick septa showed enhancement by gadolinium

\section{DISCUSSION}

The occurrence of fat necrosis in lipoma is uncommon, and few cases have been reported [3]. Most of the reported cases of lipoma with fat necrosis were enormous. In view of their large size, the main cause of fat necrosis in lipoma might be ischemia induced by trauma or tumor enlargement.

There are some imaging studies including MRI, CT and ultrasonography (US). MRI has a higher sensibility for soft tissue detail compared to CT. The advantage of US includes its wide availability and its ability to perform a dynamic and color Doppler scan at the time of the investigation, though its limitations arise when the mass is large or deep [4].
Therefore, MRI has been largely used in the diagnosis of such soft tissue tumors. In general, a lipoma takes the form of a homogeneous small mass composed of adipose tissue in MRI. A benign lipoma sometimes has intrinsic thin septa $(<2 \mathrm{~mm})$ that usually do not show enhancement by gadolinium [5].

Kransdorf et al., [6] described features favoring a diagnosis of a typical lipomatous tumor rather than lipoma as a lesion larger than $10 \mathrm{~cm}$, presence of thick septa, globular and or nodular non adipose area or mass, and decreased percentage of fat composition. And they showed the statistically significant radiologic predictors of atypical lipomatous tumor as male sex, presence of thick septa, and associated non adipose masses.

Calcification of fat necrosis has been reported, and is best appreciated with radiographs or CT. Fat necrosis can also demonstrate gallium uptake [7] on nuclear medicine studies.

Some authors [8] suggest incisional biopsy of lipomatous tumors which are indistinguishable in the imaging findings, and to take samples of not only adipose lesions, but also the thickened septa in order to reach the correct diagnosis, because of the risk of harvesting only mature adipose tissue in lipomatous regions.

\section{CONCLUSION}

A lipoma with fat necrosis may show similar MRI imaging findings to atypical lipomatous tumor. Therefore, it is important to confirm the diagnosis histologically, when we encounter a lipomatous tumor 
that imaging findings indicate to be atypical lipomatous tumor.

\section{REFERENCES}

1. Nakamura Y, Fujisawa Y, Obara S, Saito A, Nakamura Y, Kawachi Y, Otsuka F. Giant lipoma with fat necrosis of the back mimicking atypical lipomatous tumor in MRI findings, J Clin Exp Dertamol Res. S6: 13.

2. Carasso S, Oren I, Alroy G, Krivoy N. Disseminated fat necrosis with asymptomatic pancreatitis: a case report and review of the literature. Am J Med Sci, 2000; 319:68-72.

3. López Soriano A, Tomasello A, Luburich P, Noel A. Fat necrosis in a chest wall lipoma. AJR Am J Roentgenol. 2004; 183:866.

4. Jaovisidha S, Suvikapakornkul Y, Woratanarat P, Subhadrabandhu T, Narthanarung A, Siriwongpairat P. MR imaging of fat-containing tumours: the distinction between lipoma and liposarcoma. Singapore medical journal. 2010 May 1;51(5):418-423.

5. Murphey MD, Carroll JF, Flemming DJ, Pope TL, Gannon FH, Kransdorf MJ. From the archives of the AFIP: benign musculoskeletal lipomatous lesions. Radiographics. 2004 Sep;24(5):1433-66.

6. Kransdorf MJ, Bancroft LW, Peterson JJ, Murphey MD, Foster WC, Temple HT. Imaging of fatty tumors: distinction of lipoma and welldifferentiated liposarcoma. Radiology. 2002 Jul;224(1):99-104.

7. Wolpe FM, Chandarlapaty SK, Jacobi JD, Wells M, Rosenthal S. Gallium uptake in a paraplegic patient with bilateral lower extremity fat necrosis. Clin Nucl Med. 1989 Dec;14(12):930.

8. Gaskin CM, Helms CA. Lipomas, lipoma variants, and well-differentiated liposarcomas (atypical lipomas): results of MRI evaluations of 126 consecutive fatty masses. American Journal of Roentgenology. 2004 Mar;182(3):733-9. 